\title{
Downregulation of miR-382 by propranolol inhibits the progression of infantile hemangioma via the PTEN-mediated AKT/mTOR pathway
}

\author{
DONGFAN LI ${ }^{1}$, PENG $\mathrm{LI}^{2}$, ZHENGTUAN GUO ${ }^{2}$, HUAIJIE WANG ${ }^{2}$ and WEIKANG PAN ${ }^{2}$ \\ ${ }^{1}$ Department of Respiratory Medicine, The Xi'an Central Hospital of Xi'an Jiaotong University; ${ }^{2}$ Department of Pediatric Surgery, \\ The Second Affiliated Hospital of Xi'an Jiaotong University, Xi'an, Shaanxi 710004, P.R. China
}

Received September 4, 2015; Accepted December 28, 2016

DOI: 10.3892/ijmm.2017.2863

\begin{abstract}
Approximately $10 \%$ of infantile hemangiomas (IHs) are the most common vascular tumors affecting children and are characterized by rapid growth, and can have destructive, disfiguring and even life-threatening consequences. Currently, propranolol is considered to be a safe and effective treatment option for problematic proliferating IHs. Recent studies have also revealed that microRNAs (miRNAs or miRs) play important roles in the regulation of angiogenesis. In this study, XPTS-1 cells were used as a hemangioma-derived endothelial cell line constructed in our laboratory. Through a series of experiments, we discovered that miR-382 is a novel miRNA associated with IHs, which was overexpressed in XPTS-1 cells and was conversely downregulated by treatment with propranolol. In addition, we found that miR-382 contributes to the progression of IHs. Our results revealed that propranolol inhibited XPTS-1 cell migration and proliferation, and promoted apoptosis, and these effects were reversed by the restoration of miR-382 expression by transfection of the cells with an miR-382 overexpression vector. Further experiments revealed that the above-mentioned effects were associated with the phosphatase and tensin homolog (PTEN)-mediated AKT/mammalian target of rapamycin (mTOR) signaling pathway. The expression of PTEN was upregulated, while that of p-AKT, p-mTOR and
\end{abstract}

Correspondence to: Dr Peng Li, Department of Pediatric Surgery, The Second Affiliated Hospital of Xi'an Jiaotong University, 157 West 5th Road, Xi'an, Shaanxi 710004, P.R. China

E-mail: pengli_lp@163.com

Abbreviations: IHs, infantile hemangiomas; miR-382, microRNA 382; miR-1, microRNA 1; PTEN, phosphatase and tensin homolog; PI3K, phosphoinositide 3-kinase; FITC, isothiocyanate; FBS, fetal bovine serum

Key words: propranolol, infantile hemangioma, microRNA 382, phosphatase and tensin homolog, AKT/mammalian target of rapamycin pathway
p-p70S6K was downregulated by propranolol; these effects were partly reversed by the overexpression of miR-382. On the whole, our study identified that the downregulation of miR-382 by propranolol inhibits the progression of IHs via the PTENmediated AKT/mTOR pathway.

\section{Introduction}

Infantile hemangioma (IH), which is a benign vascular neoplasm, is the most common tumor affecting infants, resulting from the abnormal proliferation of endothelial cells and pericytes (1). A previous study demonstrated that $\mathrm{IH}$ often exhibits diverse and dramatic clinical behaviors (1). The majority of IHs are self-limiting, while some require specific treatment (2). Of note, the majority of lesions exhibit no potential for complications or aggressiveness (1). If left untreated, they are characterized by a rapid growth phase during the first year of life, which is then followed by slow involution spontaneously $(3,4)$. Conversely, approximately $10 \%$ of IHs exhibit rapid growth, and can have exhibit destructive, disfiguring and even vision- or life-threatening consequences, such as telangiectasias, fibro-fatty tissue, scars, excessive atrophic skin and pigment changes $(1,5)$.

Currently, the non-selective $\beta$-adrenergic-blocker, propranolol, is the preferred treatment for problematic proliferating IHs, which has been identified as a safe and effective treatment option for achieving a significant reduction in the size of IHs and lead to a considerable shortening of the natural course of IHs without any observed adverse effects (6-8). Additionally, propranolol has been shown to exert marked and rapid effects, particularly on IHs involving dyspnea, palpebral occlusion, hemodynamic compromise, or ulcerations (6). However, the mechanisms underlying the effects of propranolol have not yet been fully elucidated. The mechanisms of action of propranolol may not only involve a single mechanism, but rather to a combination of events.

MicroRNAs (miRNAs or miRs) are functional non-coding RNAs approximately 18-25 nucleotides in length, which can post-transcriptionally regulate mRNA gene expression by acting on the 3'-untranslated region (3'-UTR) of mRNAs (9). miRNAs participate in essential biological processes, including development, proliferation, cellular differentiation, stress 
responses, metabolism and apoptosis, as well as tumor initiation and progression $(10,11)$. Moreover, miRNAs play important roles in both tumor suppression and oncogene regulation and exhibit complex patterns of tissue- and disease-specific expression, having the ability to regulate many targets that are crucial to the carcinogenic process (11).

It has been previously demonstrated that propranolol induces the downregulation of miR-1 in a rat model of myocardial infarction (12), and to also the induce the downregulation of miR-382 in rat hearts (9). However, whether propranolol can regulate miR-1 and miR-382 expression in IH remains unknown. This sparked our interest in the role of these two miRNAs in propranolol-treated IHs. In the present study, we found that miR-382 was upregulated in XPTS-1 cells constructed in our laboratory when compared to the normal control, while miR-1 expression was not significantly altered. Furthermore, miR-382 was found to promote the progression of IHs and was further identified to be a target miRNA of propranolol in XPTS-1 cells, which was downregulated by propranolol treatment. Moreover, the migratory and proliferative ability of the XPTS-1 cells was inhibited by propranolol, and propranolol also promoted XTPS-1 cell apoptosis. The restoration of miR-382 expression promoted XTPS-1 cell migration and proliferation by targeting the phosphatase and tensin homolog (PTEN)-mediated AKT/ mammalian target of rapamycin (mTOR) pathway. Taken together, our findings indicate that the downregulation of miR-382 by propranolol inhibits the progression of IHs via the PTEN-mediated AKT/mTOR pathway.

\section{Materials and methods}

Cell culture. A hemangioma-derived endothelial cell line isolated from proliferating IH tissues was previously established in our laboratory and named XPTS-1 (13). The XPTS-1 cells were cultured in RPMI-1640 medium (Invitrogen, Carlsbad, CA, USA) supplemented with $10 \%$ fetal bovine serum (FBS) (Sigma-Aldrich, St. Louis, MO, USA), $10 \mathrm{ng}$ / $\mathrm{ml}$ epidermal growth factor, $100 \mathrm{U} / \mathrm{ml}$ penicillin and $100 \mu \mathrm{g} /$ $\mathrm{ml}$ streptomycin (Sigma-Aldrich) in a humidified atmosphere chamber containing $5 \% \mathrm{CO}_{2}$ at $37^{\circ} \mathrm{C}$. Human umbilical vein endothelial cells (HUVECs) were purchased from the Cell Resource Center, Shanghai Institute of Biochemistry and Cell Biology at the Chinese Academy of Sciences (Shanghai, China) and used as a control.

Treatment of XPTS-1 cells with propranolol. XPTS-1 cells $\left(2.5 \times 10^{5}\right.$ cells/well) were seeded in 6-well plates in RPMI-1640 medium with $10 \% \mathrm{FBS}, 10 \mathrm{ng} / \mathrm{ml}$ epidermal growth factor, $100 \mathrm{U} / \mathrm{ml}$ penicillin and $100 \mu \mathrm{g} / \mathrm{ml}$ streptomycin. In order to examine the effects of propranolol on XPTS-1 cells, various final concentrations of propranolol $(0,30,60,90$ and $120 \mu \mathrm{M})$ (Sigma-Aldrich) were added to the medium. Following treatment for $48 \mathrm{~h}$, the cells were collected and used to analyze the expression of miR-382 by reverse transcription-quantitative PCR (RT-qPCR).

$R T-q P C R$. Total RNA and miRNA were extracted from the XPTS-1 cell line and the HUVECs using TRIzol reagent and a PureLink miRNA Isolation kit (Invitrogen). Following quantification using a biophotometer (Eppendorf BioPhotometer Plus;
Eppendorf, Hamburg, Germany), the extracted total RNA was reverse transcribed using a High-Capacity cDNA Archive kit and a TaqMan miRNA reverse transcription kit (both from Applied Biosystems, Foster City, CA, USA) according to the manufacturers' instructions. The reverse transcription products were mixed with TaqMan universal PCR Master Mix II, and quantitative PCR (qPCR) was performed on an Applied Biosystems Prism 7500 Fast Sequence Detection system (Applied Biosystems). The primers for mRNA were as follows: miR-1 (assay ID:002222; Applied Biosystems), miR-382(miScript miR-382 primer assay kit; Qiagen, Inc., Valencia, CA, USA), PTEN (forward, 5'-GGA CGA ACT GGT GTA ATG AT-3' and reverse, 5'-TCT ACT GTT GTG AAG TAC AGC-3'). RNU48 or $\beta$-actin were used as endogenous controls. All reactions were carried out in triplicate. The mRNA and miRNA expression levels were determined using the $2^{-\Delta C_{t}}$ method.

Cell transfection. To overexpress miRNA-382, after cloning the mature miR-382 or its negative control miRNA (miR-control) into the $\mathrm{pENTR}^{\mathrm{TM}} / \mathrm{H} 1 / \mathrm{TO}$ vector (Invitrogen), the XPTS-1 cells treated with or without $120 \mu \mathrm{M}$ propranolol were transfected. Cells without transfection were used as control group. Following transfection for $24 \mathrm{~h}$, for miR-382 or mRNA PTEN analysis, total RNA was extracted using the methods described above. Total proteins were separated for western blot analysis experiments.

Transwell cell migration assay. Migration assays were performed using Transwell inserts ( $8.0 \mu \mathrm{m}$ pore size). For the migration assay, the XPTS-1 cells were treated with various final concentrations of propranolol $(0,30,60,90$ or $120 \mu \mathrm{M})$. Subsequently, approximately $2 \times 10^{4}$ cells/well in RPMI-1640 medium containing $10 \% \mathrm{FBS}, 10 \mathrm{ng} / \mathrm{ml}$ epidermal growth factor, $100 \mathrm{U} / \mathrm{ml}$ penicillin, $100 \mu \mathrm{g} / \mathrm{ml}$ streptomycin and $10 \mu \mathrm{g} / \mathrm{ml}$ mitomycin $\mathrm{C}$ were added to the upper wells. Here, mitomycin $\mathrm{C}$ was used to suppress cell proliferation. The same medium without cells was added to the lower wells. Cells that had migrated through the filter after 24,36 or $48 \mathrm{~h}$ were stained with $0.1 \%$ crystal violet (Sigma-Aldrich) and counted using a phase contrast microscope (Eclipse TE2000-U; Nikon, Tokyo, Japan), as previously described (14). The cell migration rate at $48 \mathrm{~h}$ was obtained according to the following formula: rate $=$ the number of migrated cells/the number of total cells. The same experiments were carried out on miR-382- or miR-controltransfected XPTS-1 cells, which were treated with or without $120 \mu \mathrm{M}$ propranolol for $48 \mathrm{~h}$.

Bromodeoxyuridine (BrdU) assay. The BrdU Cell Proliferation Assay kit (Cat. no 2750; Millipore Corp., Bedford, MA, USA) was used to detect cell proliferation ability according to the manufacturer's instructions. The XPTS-1 cells treated with 0 or $120 \mu \mathrm{M}$ propranolol were synchronized and plated in 96-wells $\left(3 \times 10^{3}\right.$ cells/well) in RPMI-1640 medium and $10 \mu \mathrm{l}$ BrdU solution was added followed by incubation for 24, 36 and $48 \mathrm{~h}$. Subsequently, $100 \mu \mathrm{l} /$ well of the fixing solution were added followed by incubation for $15 \mathrm{~min}$. This was followed by the addition of $100 \mu \mathrm{l} /$ well of prediluted mouse monoclonal BrdU detection antibody solution (Part no. 2750c) and further incubation for $1 \mathrm{~h}$. Subsequently, $100 \mu \mathrm{l} /$ well of prepared HRP-conjugated goat anti-mouse IgG secondary antibody (Part no. 2750e) was added followed by incubation for $30 \mathrm{~min}$. 
A

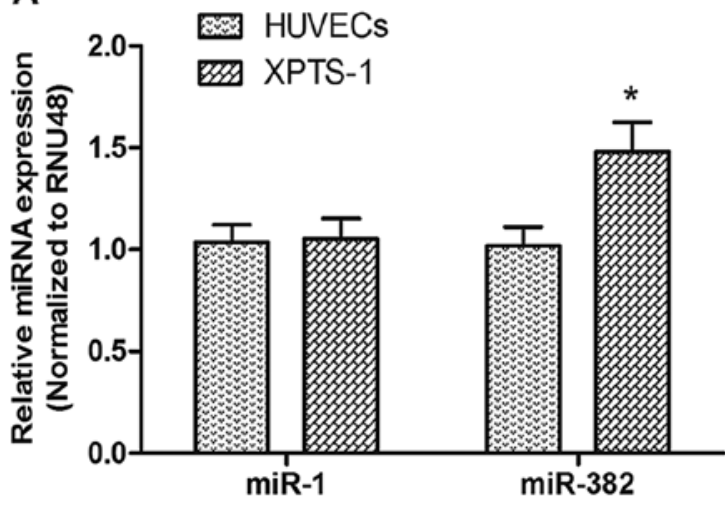

B

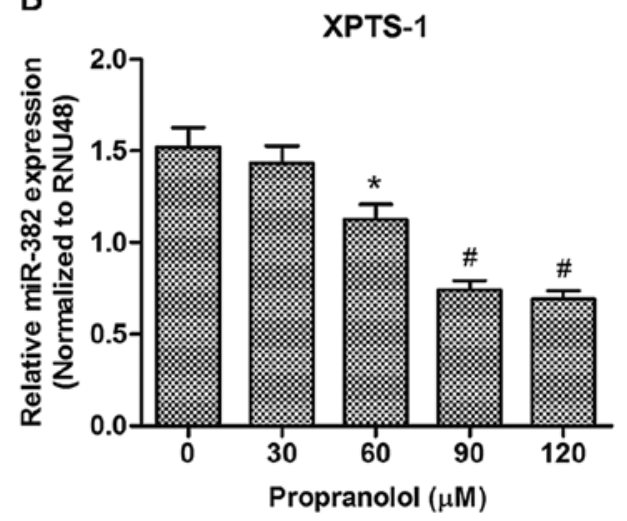

Figure 1. Relative miRNA expression in XPTS-1 cells. (A) Level of miR-1 and miR-382 mRNA in XPTS-1 cells. * $<0.05$ when compared with corresponding miRNA in human umbilical vein endothelial cells (HUVECs), as shown by the Student's t-test. (B) Level of miR-382 in propranolol-treated XPTS-1 cells. miRNA expression was examined by RT-qPCR. ${ }^{*} \mathrm{P}<0.01$ and ${ }^{*} \mathrm{P}<0.05$ when compared with miR-382 in $0 \mu \mathrm{g} / \mathrm{ml}$ propranolol-treated $\mathrm{XPTS}-1$ cells, as shown by the Student's t-test. The expression of miRNA was normalized to RNU48. Data are presented as the means \pm SD from 3 independent experiments and compared with the level of miRNA in HUVECs normalized to 1.

Finally, $100 \mu \mathrm{l}$ of TMB substrate were added before being incubated for $30 \mathrm{~min}$. The amount of BrdU incorporated into the cells was determined at $450 \mathrm{~nm}$ using a microplate reader (Benchmark 550; Bio-Rad, Hercules, CA, USA). The same experiments were carried out on miR-382- or miR-controltransfected XPTS-1 cells, which were treated with or without $120 \mu \mathrm{M}$ propranolol for $48 \mathrm{~h}$.

Apoptosis assay. Cell apoptosis was assessed by Annexin V-propidium iodide (PI). Following treatment with propranolol ( 0 or $120 \mu \mathrm{M})$ for $48 \mathrm{~h}$, floating as well as adherent cells were harvested by trypsinization (trypsin from Sigma-Aldrich) and washed with PBS. The levels of Annexin V and PI expression in the XPTS-1 cells were detected using the Annexin V-isothiocyanate (FITC) Apoptosis Detection kit (Invitrogen) according to the manufacturer's instructions. The results were analyzed using a FACSCalibur flow cytometer (BD Biosciences, Franklin Lakes, NJ, USA) within $1 \mathrm{~h}$. The same experiments were carried out on miR-382- or miR-control-transfected XPTS-1 cells, which were treated with or without $120 \mu \mathrm{M}$ propranolol for $48 \mathrm{~h}$.

Western blot analysis. The cultured XPTS-1 cells were lysed with RIPA buffer added with a cocktail of protease inhibitors (Roche Diagnostics, Indianapolis, IN, USA) for protein analysis. The protein concentration was determined using a BCA kit (Sigma-Aldrich). Target proteins were analyzed with immunoblotting following transfer onto PVDF membranes (Sigma-Aldrich) on an SDS-PAGE gel. All the primary or secondary antibodies were purchased from Abcam (Cambridge, MA, USA). Primary antibodies and anti- $\beta$-actin antibodies were added at a dilution of 1:4,000 overnight at $4^{\circ} \mathrm{C}$. HRP-conjugated secondary antibodies (ab6721) were used at 1:10,000 at room temperature for $1 \mathrm{~h}$. The reactive bands were detected with enhanced chemiluminescence (ECL, GE Healthcare, Buckinghamshire, UK) according to the manufacturer's instructions and the relative levels of each protein to $\beta$-actin were analyzed. Quantitative analysis of the bands was determined using Gel-Pro Analyzer 4.0 software (Media Cybernetics, Bethesda, MD, USA). The primary antibodies used were as follows: PTEN (ab32199); p-AKT (p-AKT1, phospho S473, ab81283); AKT (AKT1, ab32505); p-mTOR (phospho S2448, ab109268); mTOR (ab32028); p-p70S6K (phospho $\mathrm{T} 421+\mathrm{S} 424, \mathrm{ab} 32525) ;$ p70S6K (ab32359).

Statistical analysis. Data were obtained from 3 repeated assays and are expressed as the means \pm standard deviation (SD). Differences between groups were considered statistically significant with values of $\mathrm{P}<0.01$ or $\mathrm{P}<0.05$ and were analyzed using the Student's t-test. The western blot analyses experiments were performed several times, and the results were similar in all experiments. Ultimately, the images of the blots with the best quality were selected for use.

\section{Results}

Expression of miR-382 in XPTS-1 cells. To validate the role of miR-1 and miR-382 in propranolol-treated IHs, we first detected the level of miR-1 and miR-382 in XPTS-1 cells constructed in our laboratory by RT-qPCR. HUVECs were used as a control. As shown in Fig. 1A, the expression of miR-382 in the XPTS-1 cells was significantly upregulated when compared with that in HUVECs $(\mathrm{P}<0.05)$; however, no significant differences were observed in miR-1 expression was between the two cell lines $(\mathrm{P}>0.05)$. These results suggest that miR-382 is a relevant miRNA in the progression of IH. Following treatment with propranolol at various concentrations for $48 \mathrm{~h}$, the level of miR-382 was re-detected by RT-qPCR. As shown in Fig. 1B, the expression of miR-382 was downregulated gradually with the increasing concentrations of propranolol, which indicated that propranolol decreased the expression of miR-382 in XPTS-1 cells.

Propranolol inhibits XPTS-1 cell migration and proliferation, and promotes cell apoptosis. The cell migratory ability of the propranolol-treated XPTS-1 cells was evaluated by Transwell migration assay. As shown by our results, the number of migrated cells was significantly reduced with the increasing concentrations of propranolol $(60 \mu \mathrm{M}, \mathrm{P}<0.05$; 90 and $120 \mu \mathrm{M}, \mathrm{P}<0.01$ ) for each time point (Fig. $2 \mathrm{~A}$ ). In 
A

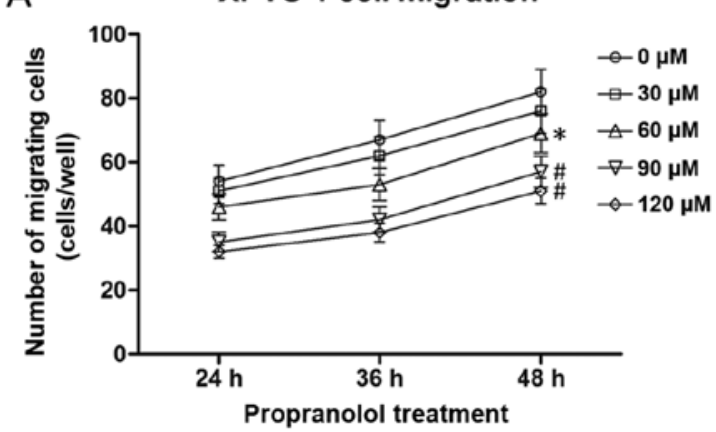

C

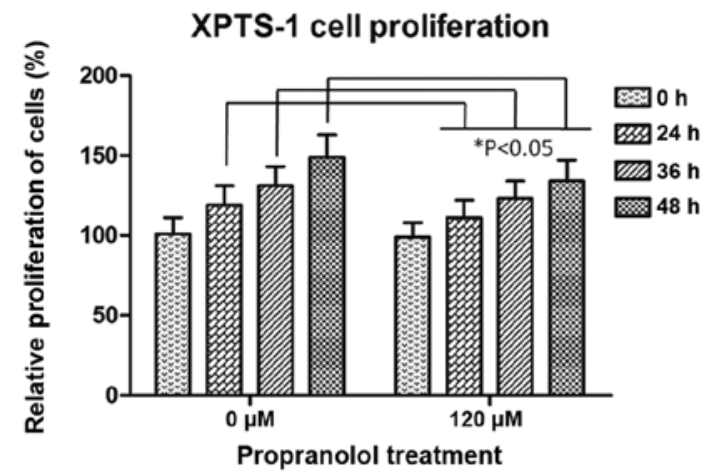

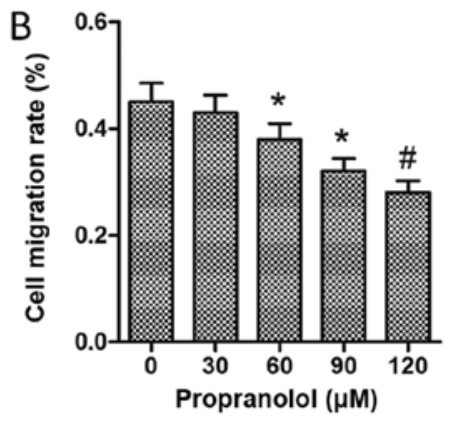
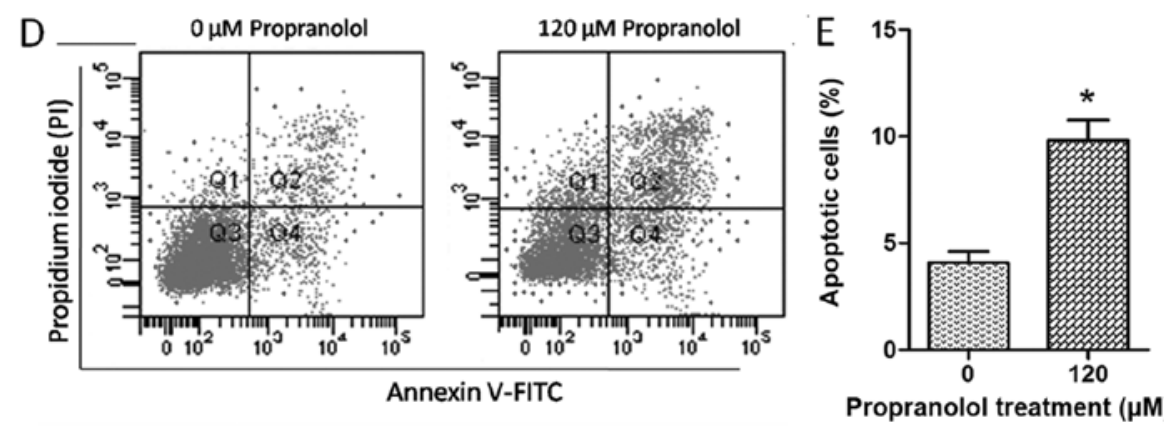

Figure 2. XPTS-1 cell migration, proliferation and apoptosis. (A) Migration of XPTS-1 cells treated with propranolol. (B) XPTS-1 cell migration rate. Cell migration rate was calculated at $48 \mathrm{~h}$ following propranolol treatment. ${ }^{\#} \mathrm{P}<0.01$ and ${ }^{*} \mathrm{P}<0.05$ when compared with $0 \mu \mathrm{M}$ propranolol, as shown by the Student's t-test. (C) Proliferation of XPTS-1 cells treated with propranolol. "P $<0.05$ when compared with the corresponding time point, as shown by the Student's t-test. Cell migration and proliferation were examined by Transwell migration assay and bromodeoxyuridine (BrdU) incorporation assay, respectively. Each assay was repeated in 3 independent experiments. Data are presented as the means \pm SD. (D) The Annexin V and propidium iodide (PI)-positive populations of XPTS-1 cells were analyzed by flow cytometry. XPTS-1 cells were pre-treated with 0 and $120 \mu \mathrm{M}$ propranolol for $48 \mathrm{~h}$, respectively. The 4 quandrants in the flow cytometry plots indicate the following: Q1, necrotic cells; Q2, late apoptotic cells; Q3, live cells; Q4, early apoptotic cells. (E) The quantification of apoptotic XPTS-1 cells. ${ }^{*} \mathrm{P}<0.05$ when compared with $0 \mu \mathrm{M}$ propranolol, as shown by the Student's t-test.

addition, the cell migration rate at $48 \mathrm{~h}$ was calculated and shown in Fig. 2B, which further verified the inhibitory effects of propranolol on XPTS-1 cell migration. On the basis of this data, cell proliferation and apoptosis were detected by BrdU incorporation assay and flow cytometry, respectively in the XPTS-1 cells treated with $120 \mu \mathrm{M}$ propranolol. As shown in Fig. 2C, the cell proliferative ability was markedly decreased by propranolol as time progressed $(24,36$ and $48 \mathrm{~h}$; $\mathrm{P}<0.05$ ), while cell apoptosis was significantly increased following treatment with propranolol (Fig. 2D and E). These results suggested that propranolol inhibited XPTS-1 cell migration and proliferation in a time- and concentrationdependent manner, and promoted XPTS-1 cell apoptosis. However, whether these effects are associated with the downregulation miR-382 remained unclear.

Overexpression of miR-382 promotes XPTS-1 cell migration and proliferation, and inhibits cell apoptosis. In order to investigate the association between the downregulation of miR-382 and decreased cell migration and proliferation, and increased cell apoptosis in XPTS- 1 cells treated with propranolol, we transfected the XPTS-1 cells with an miR-382 overexpression vector, and examined the transfection efficiency by RT-qPCR (Fig. 3A). The XPTS-1 cells were treated with or without $120 \mu \mathrm{M}$ propranolol for $48 \mathrm{~h}$. Our results revealed that the overexpression of miR-382 promoted XPTS-1 cell migration ( $\mathrm{P}<0.05$; Fig. $3 \mathrm{~B})$ and proliferation $(\mathrm{P}<0.05$; Fig. $3 \mathrm{C})$, whereas it inhibited cell apoptosis (Fig. 3D), when compared with the control (untransfected cells) or miR-control group. In this study, miR-382 was found to contribute the progression of IHs. The effects of propranolol on XPTS-1 cell migration, proliferation and apoptosis were also examined in miR-382 overexpressing XPTS-1 cells. Combined with the results in Figs. 1 and 2, we concluded that propranolol inhibited XPTS-1 cell migration and proliferation, and promoted cell apoptosis by reducing the expression of miR-382.

Overexpressiong of miR-382 inhibits PTEN expression. A previous study demonstrated that miR-328 expression induced by hypoxia promotes angiogenesis and acts as an angiogenic oncogene by suppressing PTEN (15). Based on this result, we hypothesized that the inhibitory effects of propranolol on the progression of IHs which involve the downregulation of miR-382 are also associated with PTEN. To prove our hypothesis, we detected the expression of PTEN in XPTS-1 cells treated with or without propranolol. As shown in Fig. 4A, the overexpression of miR-382 significantly downregulated PTEN expression when compared with the control (untransfected) or miR-control group $(\mathrm{P}<0.05)$. In the XPTS-1 cells treated with propranolol, which was shown to inhibit miR-382 expression, we observed that the PTEN expression level increased $(\mathrm{P}<0.01)$, which is accordance with our expectations. Hence, PTEN plays a role in the inhibitory effects of propranolol on the progression of IHs associated with the decreased expression of miR-382. When examining protein expression, similar results were observed Fig. 4B. 

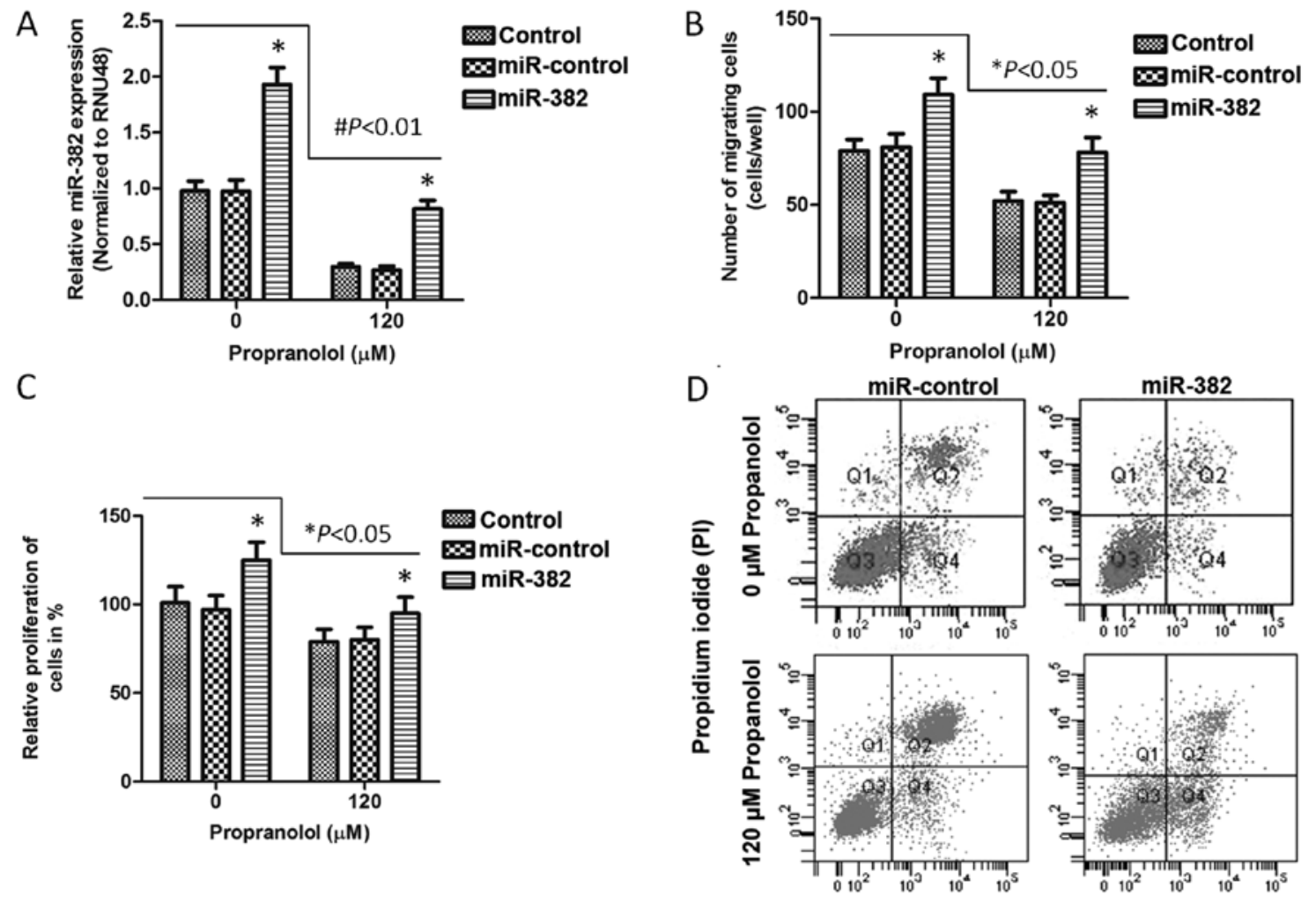

Figure 3. Cell migration, proliferation and apoptosis in miR-382 overexpressing XPTS-1 cells. XPTS-1 cells were divided into 3 groups named as follows: control (untransfected), miR-control and miR-382. All of these 3 groups were pre-treated with or without $120 \mu \mathrm{M}$ propranolol for $48 \mathrm{~h}$. (A) The XPTS-1 cells transfected with miR-382 overexpression vector were then examined by RT-qPCR. (B) The number of migrated XPTS-1 cells. (C) Relative proliferation of XPTS-1 cells. Data are presented as the means $\pm \mathrm{SD},{ }^{"} \mathrm{P}<0.01$ and ${ }^{*} \mathrm{P}<0.05$ when compared with control, as shown by the Student's t-test. (D) XPTS-1 cell apoptosis was evaluated by Annexin V-PI and detected by flow cytometry. The 4 quandrants in the flow cytometry plots indicate the following: Q1, necrotic cells; Q2, late apoptotic cells; Q3, live cells; Q4, early apoptotic cells.
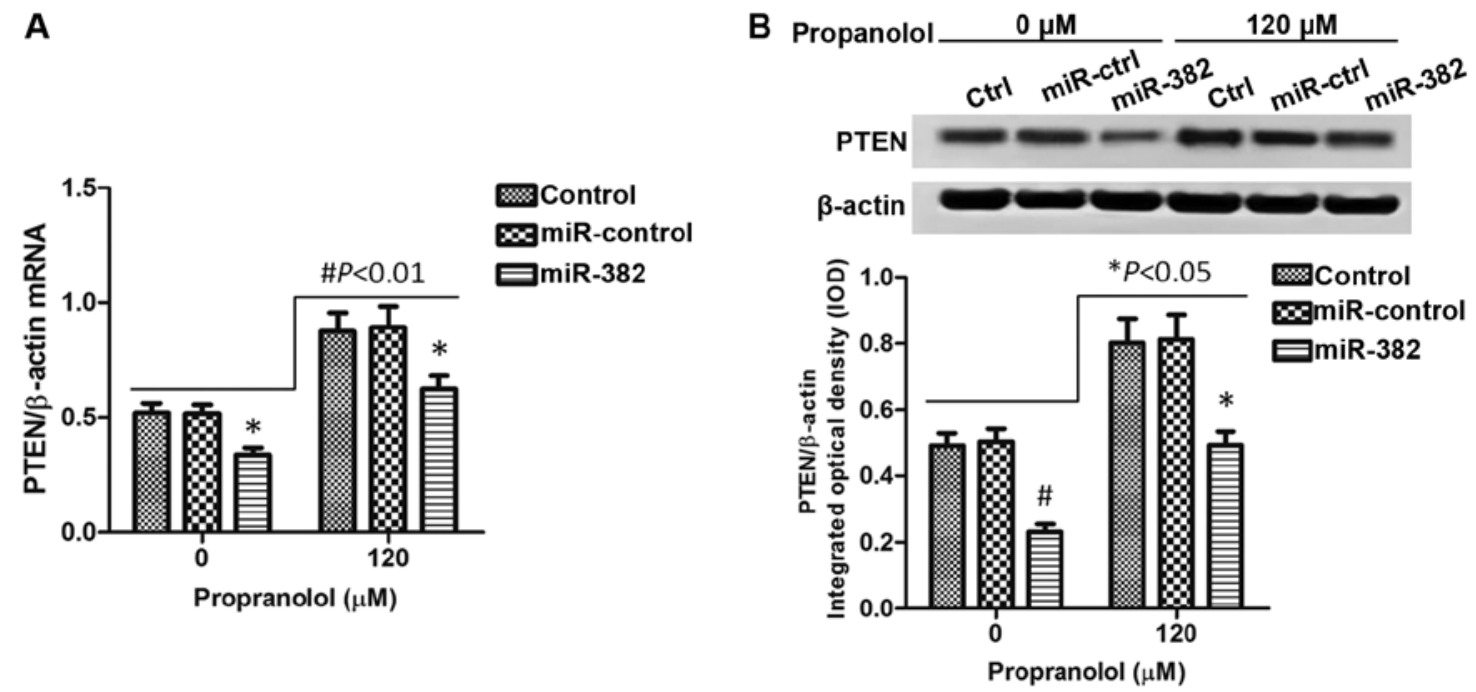

Figure 4. The expression of phosphatase and tensin homolog (PTEN) in miR-382 overexpressing XPTS-1 cells treated with propranolol. (A) The level of PTEN mRNA in XPTS-1 cells examined by RT-qPCR. (B) The level of PTEN protein in XPTS-1 cells examined by western blot analysis. Data were normalized to $\beta$-actin and presented as the mean value $\pm \mathrm{SD} .{ }^{~} \mathrm{P}<0.01$ and ${ }^{*} \mathrm{P}<0.05$ when compared with corresponding groups, as shown by the Student's $\mathrm{t}$-test. Gel-Pro Analyzer 4.0 software was used to analyze and quantify the protein bands, and data are presented as the integrated optical density (IOD).

Propranolol inhibits the AKT/mTOR signaling pathway by increasing PTEN expression. It is well known that PTEN negatively regulates the phosphoinositide 3-kinase (PI3K) signaling pathway, which is involved in intracellular signaling for cell growth, proliferation and survival $(16,17)$. As PTEN is an inhibitor of the PI3K/AKT/mTOR signaling pathway and propranolol increases PETN expression by decreasing miR-382, we hypothesized that the PI3K/AKT/mTOR signaling pathway may be inhibited in propranolol-treated XPTS-1 cells. As shown by our results of western blot analysis, the expres- 

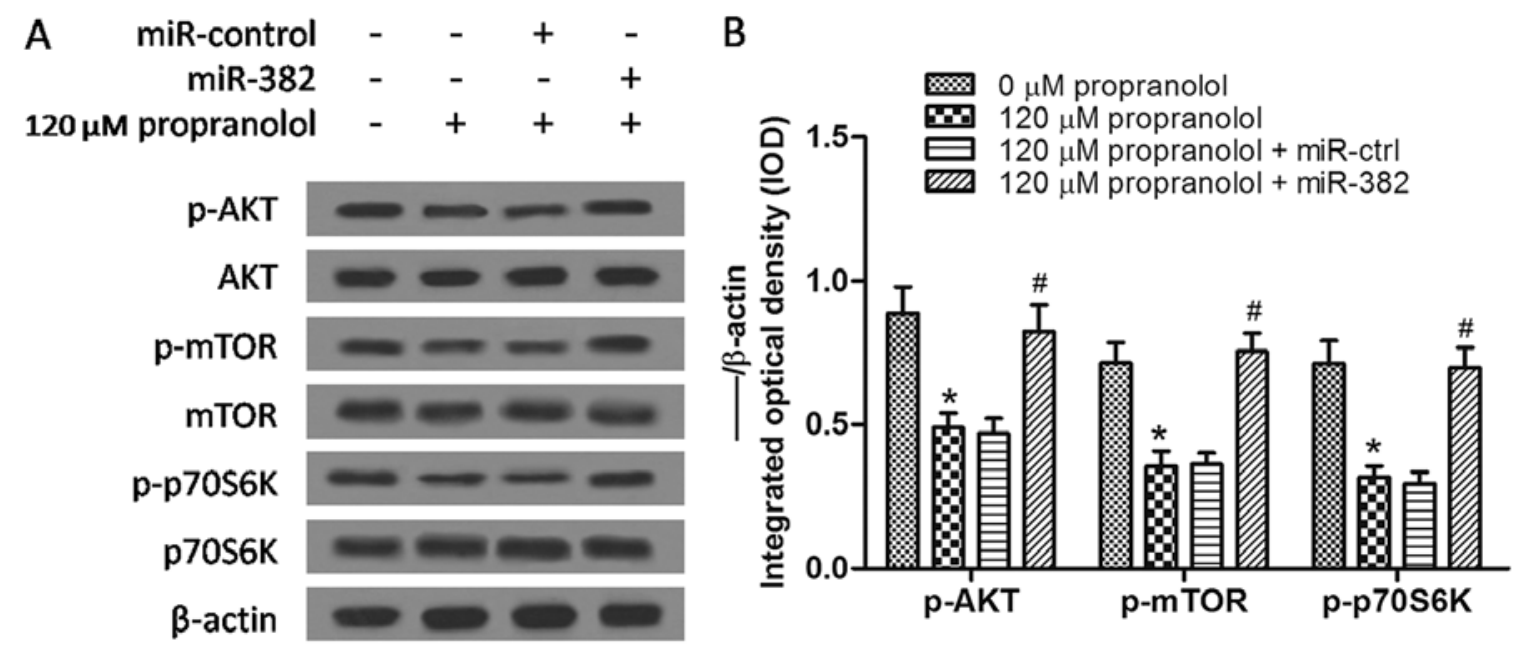

Figure 5. Propranolol inhibits the AKT/mTOR signaling pathway. (A) The expression of p-AKT, AKT, p-mTOR, mTOR, p-p70S6K and p70S6K was detected by western blot analysis. (B) Integrated optical density (IOD) of p-AKT, p-mTOR and p-p70S6K bands on PVDF membranes analyzed by Gel-Pro Analyzer 4.0 software. Data are presented as the means $\pm \mathrm{SD}$ and normalized to $\beta$-actin. ${ }^{*} \mathrm{P}<0.05$ when compared with $0 \mu \mathrm{M}$ propranolol treatment, and ${ }^{\#} \mathrm{P}<0.05$ when compared with only $120 \mu \mathrm{M}$ propranolol treatment, as shown by the Student's t-test.

sion of p-AKT, p-mTOR and p-p70S6K was downregulated by propranolol $(\mathrm{P}<0.05)$ when compared with the untreated group, and these effects were partly reversed by the overexpression of miR-382 (Fig. 5A and B). All of the above-mentioned results indicated that the downregulation of miR-382 by propranolol inhibited the progression of IHs via the PTEN-mediated AKT/ mTOR signaling pathway.

\section{Discussion}

IH is the most common tumor affecting infants, which is a benign vascular neoplasm (1). The majority of IHs have an uncomplicated course and do not require treatment, while some patients with IH experience a series of complications and require special treatment (18). Since 2008, the efficacy of propranolol in the treatment of complicated IHs has been discovered, and propranolol has become the primary treatment of choice $(19,20)$. Accumulating evidence has proven that miRNAs participate in a variety of biological and pathological processes. Altered miRNA expression has been implicated in oncogenesis $(21,22)$. In addition, propranolol has been found to regulate miRNA expression in rat hearts (9). All of the abovemeniotned findings sparked our interest in the miRNA-related mechanisms concerning the effect of propranolol in IHs.

In a previous study, we established the hemangioma-derived endothelial cell line from proliferating IH tissues and named these cells XPTS-1 (13). We first determined that miR-382 was upregulated in the XPTS-1 cells and was downregulated following treatment with propranolol, which indicated that miR-382 is a novel IH-relevant miRNA regulated by propranolol. We then discovered that propranolol inhibited the migration and proliferation of XPTS-1 cells, and promote cell apoptosis. The inhibitory effect of propranolol on tumor progression has also been reported in breast cancer (23), intracerebral and spinal hemangiomas (24), and tufted angioma (25). In this study, following transfection of the XPTS- 1 cells with miR-382 overexpression vector, the inhibitory effecs of propranolol on $\mathrm{IH}$ progression were reversed to a certain extent. This indicates that propranolol exerts its inhibitory effects on IH progression by targeting miR-382. We then proved that the PTEN-mediated AKT/mTOR signaling pathway plays a role in this process. In the XPTS- 1 cells, propranolol reduced miR-382 expression, and attenuated the inhibitory effects of miR-382 on PTEN expression, further promoting the suppressive effects of PTEN on the AKT/mTOR signaling pathway, and inhibiting the migration and proliferation of these cells.

The PI3K/AKT/mTOR signaling pathway plays a key role in cellular growth and survival, which has been implicated in the pathogenesis of a variety of tumors (26-28). Hence, the inhibition of the PI3K/AKT/mTOR pathway is of therapeutic interest. Although the PI3K/AKT/mTOR signaling pathway has been predicted to be implicated in IHs (1), the exact role of this pathway has not yet been fully described. In the present study, we indentified that the PTEN-mediated AKT/mTOR signaling pathway is downstream of miR-382, which is regulated by propranolol.

In conclusion, the findings of our study indicated that downregulation of miR-382 by propranolol inhibited the progression of IHs via the PTEN-mediated AKT/mTOR signaling pathway. Our study provides new insight and mechanisms to explain the functions of propranolol in IHs. In the future, we aim to conduct further research to sufficiently justify this mechanism at the organism level in IHs.

\section{Acknowledgements}

The present study was supported by grants from the National Natural Science Foundation of China (no. 81172589).

\section{References}

1. Ji Y, Chen S, Li K, Li L, Xu C and Xiang B: Signaling pathways in the development of infantile hemangioma. J Hematol Oncol 7: $13,2014$.

2. Yilmaz L, Dangoisse $C$ and Semaille P: Infantile hemangioma and propranolol: a therapeutic 'revolution'. Literature review. Rev Med Brux 3: 4479-4484, 2012. 
3. Mulliken JB, Fishman SJ and Burrows PE: Vascular anomalies. Curr Probl Surg 37: 517-584, 2000.

4. Drolet BA, Esterly NB and Frieden IJ: Hemangiomas in children. N Engl J Med 341: 173-181, 1999.

5. Margileth AM and Museles M: Cutaneous hemangiomas in children. Diagnosis and conservative management. JAMA 194: 523-526, 1965.

6. Ji Y, Chen S, Xu C, Li L and Xiang B: The use of propranolol in the treatment of infantile haemangiomas: an update on potential mechanisms of action. Br J Dermatol 172: 24-32, 2015.

7. England RW, Hardy KL, Kitajewski AM, Wong A, Kitajewski JK Shawber CJ and Wu JK: Propranolol promotes accelerated and dysregulated adipogenesis in hemangioma stem cells. Ann Plast Surg 73 (Suppl 1): S119-S124, 2014

8. Laranjo S, Costa G, Paramés F, Freitas I, Martins JD, Trigo C and Pinto FF: The role of propranolol in the treatment of infantile hemangioma. Rev Port Cardiol 33: 289-295, 2014.

9. Hou Y, Sun Y, Shan H, Li X, Zhang M, Zhou X, Xing S, Sun H, Chu W, Qiao G and Lu Y: $\beta$-adrenoceptor regulates miRNA expression in rat heart. Med Sci Monit 18: BR309-BR314, 2012.

10. Gaedcke J, Grade M, Camps J, Søkilde R, Kaczkowski B Schetter AJ, Difilippantonio MJ, Harris CC, Ghadimi BM, Møller S, et al: The rectal cancer microRNAome - microRNA expression in rectal cancer and matched normal mucosa. Clin Cancer Res 18: 4919-4930, 2012.

11. Slattery ML, Wolff E, Hoffman MD, Pellatt DF, Milash B and Wolff RK: MicroRNAs and colon and rectal cancer: differential expression by tumor location and subtype. Genes Chromosomes Cancer 50: 196-206, 2011.

12. Lu Y, Zhang Y, Shan H, Pan Z, Li X, Li B, Xu C, Zhang B, Zhang F, Dong D, et al: MicroRNA-1 downregulation by propranolol in a rat model of myocardial infarction: a new mechanism for ischaemic cardioprotection. Cardiovasc Res 84 434-441, 2009

13. Li P, Xiao XE, Xu Q and Guo ZT: Establishment of human infancy hemangioma-derived endothelial cell line XPTS-1 and animal model of human infancy hemangioma. Zhonghua Kou Qiang Yi Xue Za Zhi 46: 129-133, 2011 (In Chinese).

14. Han L, Liang XH, Chen LX, Bao SM and Yan ZQ: SIRT1 is highly expressed in brain metastasis tissues of non-small cell lung cancer (NSCLC) and in positive regulation of NSCLC cell migration. Int J Clin Exp Pathol 6: 2357-2365, 2013.

15. Seok JK, Lee SH, Kim MJ and Lee YM: MicroRNA-382 induced by HIF-1 $\alpha$ is an angiogenic miR targeting the tumor suppressor phosphatase and tensin homolog. Nucleic Acids Res 42: 8062-8072, 2014
16. Snaddon J, Parkinson EK, Craft JA, Bartholomew C and Fulton R: Detection of functional PTEN lipid phosphatase protein and enzyme activity in squamous cell carcinomas of the head and neck, despite loss of heterozygosity at this locus. Br J Cancer 84: 1630-1634, 2001.

17. Blanco-Aparicio C, Renner O, Leal JF and Carnero A: PTEN, more than the AKT pathway. Carcinogenesis 28: 1379-1386, 2007.

18. Haggstrom AN, Drolet BA, Baselga E, Chamlin SL, Garzon MC, Horii KA, Lucky AW, Mancini AJ, Metry DW, Newell B, et al: Prospective study of infantile hemangiomas: clinical characteristics predicting complications and treatment. Pediatrics 118: 882-887, 2006.

19. Léauté-Labrèze C, Dumas de la Roque E, Hubiche T, Boralevi F, Thambo JB and Taïeb A: Propranolol for severe hemangiomas of infancy. N Engl J Med 358: 2649-2651, 2008.

20. Drolet BA, Frommelt PC, Chamlin SL, Haggstrom A, Bauman NM, Chiu YE, Chun RH, Garzon MC, Holland KE, Liberman L, et al: Initiation and use of propranolol for infantile hemangioma: report of a consensus conference. Pediatrics 131 128-140, 2013.

21. Zhang B, Pan X, Cobb GP and Anderson TA: microRNAs as oncogenes and tumor suppressors. Dev Biol 302: 1-12, 2007.

22. Li W, Xie L, He X, Li J, Tu K, Wei L, Wu J, Guo Y, Ma X, Zhang P, et al: Diagnostic and prognostic implications of microRNAs in human hepatocellular carcinoma. Int J Cancer 123: 1616-1622, 2008.

23. Abdin AA, Soliman NA and Saied EM: Effect of propranolol on IL-10, visfatin, Hsp70, iNOS, TLR2, and survivin in amelioration of tumor progression and survival in Solid Ehrlich Carcinoma-bearing mice. Pharmacol Rep 66: 1114-1121, 2014.

24. Miquel J, Bruneau B and Dupuy A: Successful treatment of multifocal intracerebral and spinal hemangiomas with propranolol. J Am Acad Dermatol 70: e83-e84, 2014.

25. Yamamoto Y, Kounami S, Okuhira H, Nakamura $Y$ and Furukawa F: Successful treatment of tufted angioma with propranolol. J Dermatol 41: 1120-1122, 2014.

26. Lamming DW, Ye L, Sabatini DM and Baur JA: Rapalogs and mTOR inhibitors as anti-aging therapeutics. J Clin Invest 123 : 980-989, 2013

27. Benjamin D, Colombi M, Moroni C and Hall MN: Rapamycin passes the torch: a new generation of mTOR inhibitors. Nat Rev Drug Discov 10: 868-880, 2011.

28. Slomovitz BM and Coleman RL: The PI3K/AKT/mTOR pathway as a therapeutic target in endometrial cancer. Clin Cancer Res 18 5856-5864, 2012. 